\title{
Strategies for Improving Human Resource Management in Logistics Enterprises
}

\author{
Hua Li
}

\begin{abstract}
Jiangxi Vocational Technical College Of Industry \& Trade, Jiangxi, Nanchang, 330038
739960103@qq.com
\end{abstract}

\begin{abstract}
Driven by the Internet economy, the logistics industry is obviously in a rapidly rising stage of development, and every industry needs a lot of human resources in the rapidly rising stage. Although the number of students graduated from college logistics management is also very large every year, the number of graduates is far less than the number needed for the development of the industry. In particular, the current training direction of logistics management professionals in colleges and universities is not very consistent with the development direction of the industry, so some logistics management graduates cannot provide impetus for the development of the industry, so logistics enterprises can only improve human resources management to ensure the sustainable development of enterprises. This paper also focuses on the improvement strategy of human resource management in logistics enterprises.
\end{abstract}

Keywords : logistics enterprise, human resource management, improvement strategy, research

\section{物流企业人力资源管理改进策略探微}

\author{
黎华
}

江西工业贸易职业技术学院 江西 南昌 330038

739960103@qq.com

\begin{abstract}
摘要
在互联网经济的推动下, 物流行业很明显处于一个急速上升的发展阶段, 而每一个行业在急速上升阶段, 都需 要大量的人力资源。虽然每年从高校物流管理专业毕业的学生数量也非常多, 但是毕业学生的数量远远比不上 行业发展所需求的数量。尤其是当前高校物流管理专业人才培养方向与行业发展方向并不十分契合, 所以有部 分物流管理专业毕业生无法为行业发展提供推动力, 因此物流企业只能将通过改进人力资源管理, 来保证企业 的可持续发展。本文也主要围绕物流企业人力资源管理改进策略进行研究。
\end{abstract}

关键词: 物流企业; 人力资源管理; 改进策略; 研究

\section{1 物流企业人力资源概述}

\section{1 企业数量众多，工作规范尚不健全}

我国物流行业的发展时间相较于发达国家的物 流行业的发展时间较晚, 但是我国物流行业的发展速 度却十分可观, 而由于我国物流行业的发展情况以及 市场经济情况影响, 我国物流企业大部分都是中小型 企业，少数的大型物流企业的业务量则十分庞大，虽 然中小型物流企业的业务量会少于大型物流企业的
业务量, 但中小型企业也应该做到规范业务操作流 程, 但是因为目前整个物流行业都处于一个摸索发展 的阶段，所以物流企业也得不到明确的发展指向，从 而导致企业内部工作管理较为混乱，而工作管理混 乱, 工作体系不健全, 自然也会影响到企业的人力资 源管理。

\section{2 物流企业经营地域广阔，人员管理困难}

物流企业是需要跨越地域来进行经营的, 所以物 
流企业的经营范围也需要非常广阔才能够给物流企 业提供一定的经营利润。而为了拓宽市场, 拓宽经营 范围, 物流企业就需要在不同的地域设置经营网点又 或是分公司, 这样就能够尽快的囊括更多的地区物流 市场。但是这样的方式又很难对地区人力资源进行管 理, 并且网点落实情况较为不理想, 总公司也很难对 分公司的经营情况和人力资源管理情况进行监管。

\section{3 企业用工量大，看重员工的服务意识}

物流企业需要更多的物流管理专业人才, 不然难 以应付物流业务量的增长, 并且物流企业所设置的网 点数量越多, 所跨越的地域越大, 就需要更多的中高 层管理人员, 因为基层物流操作人员只能够承担基层 工作, 但是中高层管理人员能够为物流企业进行经营 策划和企业管理。除了除此之外, 物流企业的员工服 务意识需要得到提升, 因为物流企业也属于服务, 企 业经营目的是为了给客户提供客户所需要的服务。

表 1 物流企业人力资源概述

\begin{tabular}{|c|c|c|}
\hline \multicolumn{3}{|c|}{ 物流企业人力资源概述 } \\
\hline $\begin{array}{c}\text { 企业数量众多, } \\
\text { 工作规范尚不健 } \\
\text { 全 }\end{array}$ & $\begin{array}{c}\text { 物流企业经营地 } \\
\text { 域广阔, 人员管 } \\
\text { 理困难 }\end{array}$ & $\begin{array}{c}\text { 企业用工量大, } \\
\text { 看重员工的服务 } \\
\text { 意识 }\end{array}$ \\
\hline $\begin{array}{c}2013 \text { 年德邦才开 } \\
\text { 始新增快递业 } \\
\text { 务, } 2015 \text { 年双十 } \\
\text { 一第一次加入菜 } \\
\text { 鸟网络的配送体 } \\
\text { 系, 快递业务的 } \\
\text { 操作流程还处于 } \\
\text { 探索阶段, 像德 } \\
\text { 邦快递这样缺乏 } \\
\text { 行业操作经验的 } \\
\text { 物流公司数量众 } \\
\text { 多。 }\end{array}$ & $\begin{array}{l}\text { 由于物流企业的 } \\
\text { 经营通常需要跨 } \\
\text { 地域设置下属分 } \\
\text { 公司或经营网 } \\
\text { 点, 人员下派到 } \\
\text { 分公司或经营网 } \\
\text { 点, 涉及的地域 } \\
\text { 比较广阔, 总公 } \\
\text { 司的各项人力资 } \\
\text { 源管理制度在分 } \\
\text { 公司或经营网点 } \\
\text { 落实较差, 从监 } \\
\text { 督的角度来说, } \\
\text { 监管难度较大。 }\end{array}$ & $\begin{array}{c}\text { 作为服务行业, } \\
\text { 员工的服务意识 } \\
\text { 非常重要, 因为 } \\
\text { 物流公司各个岗 } \\
\text { 位之间需要相互 } \\
\text { 配合有效衔接, } \\
\text { 才能最终实现高 } \\
\text { 效地为客户提供 } \\
\text { 满意服务的目 } \\
\text { 的。 }\end{array}$ \\
\hline
\end{tabular}

\section{4 物流企业对相关专业的专业性和素质要求 较高}

物流领域中对相关技术的要求不断增加, 物流企 业对这方面的投入也逐渐增加起来, 对员工的专业要 求也越来越高, 企业也鼓励员工进行相关技能的培训 对自身技能进行相应的提升, 企业方面也给予很多培 训机会让员工能够进一步掌握专业技能知识, 提高实 际操作技能, 这样也能够进一步保障对一些专业设备 的安全操作, 同时也能够给企业带来相应的经济效 益, 给企业降低经济上的损失, 保障生产成本的稳定。
物流公司通过这些培训对自身的专业技能进行替身, 专业素养也得到提升。

\section{2 物流企业人力资源管理存在的主要问题}

\section{1 用人之道问题}

企业需要改变人力资源管理理念, 用先进的人力 资源管理理念合理配置人力资源, 减少企业的不必要 的损失，提高企业的工作效率，但是同时企业也应该 坚持对企业而言有益的人力资源管理方法, 将传统的 人力资源管理理念与先进的人力资源管理理念相结 合，让企业招收了充足的物流管理员工之后，对员工 进行培训, 让员工能够更加全面的了解企业的发展经 营情况, 以及企业的人力资源管理制度。但是如果企 业只一昧地招收应届毕业生, 又或是只招收经验丰富 的中高层管理人员，那么就会使得企业的人力资源管 理出现严重的倾斜问题, 而想要构建一支优秀的物流 管理人才队伍, 企业就应该将这两种人才都纳入其 中。

\section{2 没有相应的激励体制}

企业的发展需要高素质的人才, 对人才的竞争在 一定意义上也是企业之间的竞争, 物流企业只有通过 招揽高素质人才才能实现企业自身的长足发展。因此 在物流企业发展的过程中通常都会制定一系列的激 励体系对人才进行嘉奖，在工作中都会制定工作上的 绩效考核, 但绩效考核也没办法切实体现员工的工作 成果, 没办法对工作进行准确的量化, 在对员工进行 考核时也没办法进行客观的评判, 没有规范的考核标 准。同时企业在对员工进行激励时，也没有重视多元 化的奖励方式的应用，只是通过工资提成或者奖金的 形式进行发放，这种对员工的激励模式只看到员工的 物质需要, 而忽略了员工的精神需求, 在精神的需求 上可以通过职位的提升对员工能力的提升进行激励, 这样可以在一定程度上避免企业人才的流失的现象。

\section{3 不健全的培训制度}

目前市场上的大部分物流企业的培训制度都不 够合理有效, 所谓的合理有效就是企业能够通过企业 内部的培训制度, 将员工的潜能和能力全部激发出 来, 并通过员工的能力来推动企业的发展, 但是目前 物流企业所能够做到的, 只是通过培训让员工更加了 解物流企业, 了解企业内部的制度以及自己的工作职 责和工作范围, 并且企业在培训的过程中, 忽略了对 员工进行企业文化认同的培训, 使得员工的流失率非 常大。

\section{4 高素质人才的缺失}

目前物流管理人才的培养很大程度上都十分依 赖于高校进行人才的培养, 高校在专业人才的培养上 也存在着很多的缺陷, 比如大部分物流专业的课程教 
学和教学目标都过分重视专业理论知识, 对实践部分 的培养并不多, 或者对学生实践部分的培养实际操作 起来存在很多问题, 比如高素质教师的稀缺、专业设 备的缺失等等, 这些都是导致物流专业人才在毕业后 无法快速进入高层管理工作的原因，专业高素质人才 的缺失就导致企业方面对人才市场中有限的高素质 人才进行抢夺，更多具备管理阶层经验的人才也被企 业方面所青睐。

\section{5 人力资源管理理念被局限}

在物流企业人力管理工作中存在一些观念上的 局限性, 这种局限性主要体现在以下几个方面, 第一 就是企业中的领导层面并没有意识带人力资源管理 的重要性, 对这部分的工作并没有起到重视, 因此也 没有对相关的人才进行培养, 也没有这种培养意识, 这种企业管理层级的观念的限制对企业中的人力资 源管理十分不利, 因此在很多时候企业中的人力资源 管理工作并不能十分顺利地开展。第二, 在物流企业 中对人力资源人员的培养工作并不完善, 对于人力资 源相关人员的培养很容易流于表层, 对相关人员的培 训工作效率十分低下。第三, 物流企业并没有根据公 司本身的实际情况进行相应的人力资源管理体系, 形 成一套公司自身的人力资源部门发展的规划以及人 力资源的管理的概念, 企业员工的专业素养得不到培 养, 物流企业中人力资源的管理的优势也就无法发挥 出来。

\section{6 专业物流人才队伍建设并不完善}

在国内的物流企业中普遍都存在没有完善的培 训体系的问题, 究其原因, 部分是由于当下高校物流 行业中的人力资源专业并没有对相关人才进行综合 性素质的培养, 存在着过于重视理论知识, 没有对实 践操作和相关专业新技术应用给予相应的重视, 这样 的高校培养体系注定无法培养出高素质人力资源管 理人才, 学生在走入工作岗位后也无法快速适应工作 岗位, 也没有很多的实践性经验, 也很难成为企业中 的高层级的管理人员。但高素质的物流企业管理人才 在市场上是十分欠缺的, 要想成为物流管理专业的高 素质人才首先就要具备物流专业丰富的管理的理论 知识, 同时也要对行业相关的高科技技术有一定的了 解和实践, 此外还有一个很重要的因素是企业并没有 对物流人才的培养建设投入管理精力, 很多物流企业 中对于员工的相关技能的培养没有从深层次进行, 很 多培训都只是做做表面上的功夫, 比如给员工进行专 业知识的宣讲, 这类对专业知识的宣讲并不能起到很 好的培训提升效果。这种活动也没有针对每个部门的 具体情况进行具体分析, 进行针对性的开展培训活 动, 从而对员工的专业能力进行提升, 顺应物流行业 中的发展趋势。

\section{3 改进物流企业人力资源管理的策略}

\section{1 转变企业经营观念, 注入先进的管理理念}

因为物流企业本身的经营理念就存在问题, 与时 代格格不入, 所以物流企业的人力资源管理现状才会 不如人意。在刚开始起步的阶段, 物流企业想要通过 当前的经营理念来促进企业的发展是可行的，但是在 物流企业已经进入到正式发展的队列当中时, 当前的 经营理念就不能够再体现出其根本价值了。转变经营 理念, 吸取先进的管理理念, 才是物流企业当下所需 要做的。并且在物流企业吸收了先进的管理理念之 后, 还应该根据先进的管理理念, 改变企业战略计划, 为企业的可持续发展做好准备, 同时企业也应该完善 绩效考核制度，通过合理的绩效考核方式，激励员工 为企业的发展而奋斗。

\section{2 加强激励体系建设}

在建立激励体系时, 企业应该注意对企业文化的 建设, 因为企业文化能够激励学生企业归属感, 也能 够帮助企业将员工凝聚在一起, 而想要发挥出企业文 化的价值, 企业就必须要对员工进行培训, 让员工深 刻的了解企业的文化, 在员工认同了企业文化之后, 员工自然就会为企业的发展提供更大的助力。而对员 工进行激励, 可以从物质激励和精神激励两方面着 手, 所谓的物质激励也就是从工资或是奖金等方面来 激励员工加倍努力的工作, 例如员工工作表现优异, 企业就能够为员工发放一定额度的奖金或是提高员 工的工资。一方面是表扬员工的工作表现，激励员工 继续保持。精神激励也就是通过满足员工的精神需 求, 来使员工从内部得到工作动力, 而最好的激励方 式也就是物质激励和精神激励双管齐下。在对物流企 业中的人力资源管理人员进行激励体系的构建时要 多多借鉴发达国家的经验, 吸取他们在企业中对人才 进行激励的模式, 同时也要对人员进行及时的更换, 从而来达到有效的激励作用。企业中的人力资源管理 中也要从员工的角度出发, 只有这样从员工的角度来 考虑, 同时设置一些经济上的奖赏和精神上的奖励, 这样才能够充分发挥企业中的激励制度的最大化作 用。

\section{3 对专业人才进行培养和引进}

高素质人才对于企业的发展起到的促进作用是 不言而喻的, 在物流行业更是如此, 其根本原因是物 流行业对人才的专业技能要求较高, 因此更加需要一 些专业技能强的高水平的物流人才。企业方面需要重 视对人才进行引进, 将人才的引进工作作为企业的重 要部分进行开展, 让高素质专业人才给企业发展起到 推动作用。物流企业的人力资源管理部门要做好对专 业人才的保障工作, 不仅仅要保障物流人才的薪资和 生活, 同时也要提供一个好的工作学习环境, 这就需 要搭建一个培训平台, 帮助他们进行学习和提升自 
身, 自身能力能够在物流企业中得到充分发挥。因此 在物流企业中对人才的引进和培养都是十分重要的 工作，只有人力资源管理人员对物流企业人员进行科 学正确的培训和对物流人才进行引进, 才能持续不断 的发挥出物流企业人才的能力, 以达到对专业人才能 力提升的效果, 这样才能将企业竞争力进行提高, 促 进企业的长远发展。

\section{4. 结论}

综上所述, 物流行业的发展在信息时代背景下是 必然的, 从此也可以窥见物流企业的发展形式是一片 大好的。同时人力资源管理也是企业发展的一个重要 部分, 因此在物流企业中的管理层级必须要认识到对 人力资源管理进行改进的重要作用, 如果物流企业依 然固守传统的管理理念和人力资源管理办法, 是无法 得到长足的进步的, 因此物流企业需要改变管理理 念, 改进人才资源管理, 通过实施这些措施来推动企 业发展。

\section{REFERENCES}

[1] Qian Yu, Gui Ting, Liu Shuping. Research on Optimization of Logistics Management Talent Training Mode Based on "1+X" Certificate System -- Taking Shanghai Jiaotong Vocational and Technical College as an Example [J]. Science and Education Wenhui (Medium Issue),2020(12):142-143.

[2] Wang Yangjun, Zheng Jun. Research on the Innovative Practice of Talent Cultivation Mode of "Leading Enterprises into School" in Higher Vocational Colleges -- Taking Logistics Management Major of Hunan Vocational and Technical College of Engineering as an Example [J]. Journal of Hunan Socialism University,2020,21(06):94-96.

[3] Wang Zhe. Exploration on the Training Path of Logistics Engineering Specialty Based on Demand Coupling -- Taking the Logistics Engineering Major of Sichuan Tourism University as an Example [J]. Logistics Science and Technology,2020,43(12):164-168.

[4] Jiang Fang. Research on Logistics Talents Training under the Condition of School-Enterprise Cooperation -- Taking the Logistics Talents Demand of Pingtan Comprehensive Experimental Area as an Example [J]. Inner Mongolia Science, Technology and Economy,2020(22):40-42.

[5] Mao Lixia, Zhang Rong. Analysis and Practice of Effectiveness Strategy of Teaching and Learning of Quality Resource Sharing Course Based on Problem Orientation -- Taking Logistics Cost Management Course as an Example [J]. Logistics Technology,2020,39(11):137-141.
[6] Yuan Yali. Training of Intelligent Logistics Talents in Higher Vocational Colleges under the Background of "Internet +" -- A Case Study of Shanghai Zhongqiao Vocational and Technical College [J]. Hebei Vocational Education,2020,4(05):76-78.

[7] Li Yanzhen, Su Yuna. Innovation and Practice of Logistics Management Major + Complex Talents Training Based on the Integration Education Mode of Enterprise College [J]. Logistics Technology,2020,39(09):148-151.

[8] Liu Xingui, Zhang Xiaoqing. Innovation and Practice of Talent Training in the "Last KM" of Higher Vocational Logistics Major from the Perspective of Curriculum Ideology and Politics [J]. Firework Technology and Market,2020(03):106.

[9] Anna, Zhaoshukao, Shen Aiqun. Research on the Training Reform of Higher Vocational Logistics Management Specialty Based on the Analysis of Talent Demand in Jiangsu Province [J]. The marketing world, 2020 (29) : 73-75.

[10] Bai Rumeng, Wang Qian. Digital Enabled Construction of Intelligent Resource Management System -- A Probe into the Application of Internet of Things Technology in Emergency Resource Management $[\mathrm{J}]$. China Emergency Management,2020(07):56-57.

[11] He Lin, Bian Chengmin. Analysis on the Training Mode of Logistics Management Specialty in Private Universities Based on Grey Relational Analysis [J]. Investment and Cooperation,2020(06):146-148.

[12] $\mathrm{Hu}$ Yuzhou. Research on the Innovation Ability Cultivation System of Logistics Management Major Students in Applied Universities [J]. Logistics Science and Technology,2020,43(06):171-174.

[13] Shen Liang, Li Hui. Analysis on the countermeasures of optimizing logistics resource management of small and medium-sized logistics management enterprises under the new situation [J]. Knowledge economy,2014(18):87+94.

[14] Wang Chuanlei, Wang Ruzheng, Liu Xinyan. Information Resource Management of Social Enterprises in Transition: A Case Study of Three Enterprises $\quad[\mathrm{J}]$. Journal of Information,2011,30(09):173-179.

[15] Dong Hui. Current Situation and Development Trend of Computer-Aided Instruction in Information Resource Management Talent Training [J]. Library and Information Knowledge,1999(01):25-27. 